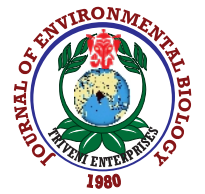

\title{
Assessment of relationship between the surface temperatures and built-up urban environment in Ankara city center
}

\author{
D.H. Somuncu* and Ü. Yüksel ${ }^{2}$ \\ ${ }^{1}$ Ankara Provincial Directorate of Environment and Urbanization, Ankara, 06650, Turkey \\ ${ }^{2}$ Department of Urban and Regional Planning, Gazi University, Ankara, 06570, Turkey \\ *Corresponding Author Email : dhilald12@hotmail.com
}

\begin{abstract}
Aim: This study focuses on determining relationship between the surface temperatures of Ankara (Turkey) - thermal load in this regard - and built-up environment of city using Local Climate Zone system.

Methodology: This study consists of two basic stages: formation of thermal load map and analysis of relationship between surface temperatures, the LCZs, and the built-up environment by determining these LCZs. Firstly, metadata from Landsat 8-OLI satellite images were used to perform the surface temperature analysis, than building surface fractions, and building height figures were analyzed, and the thermal load in the area was determined. Pearson's correlation analysis was performed to assess the relationship between surface temperature, building surface fraction and building height. One-way analysis of variance (ANOVA) was conducted to see difference between the surface temperatures regarding LCZs. Tukey's test, one of multiple comparison (Post $\mathrm{Hoc}$ ) tests used in one-way variance analysis, was performed to compare the groups with each other.

Results: According to assessment of surface temperatures by LCZs, the lowest temperature $\left(33.0^{\circ} \mathrm{C}\right)$ was seen in LCZ-A with a dense tree pattern, while the highest value $\left(44.5^{\circ} \mathrm{C}\right)$ was detected in LCZ-8 which had buildings with low stories on a broad base and impervious neighboring areas. This study evaluated whether there was a relationship between surface temperature, building fractions, and building height in terms of LCZs. A relationship was found between the surface temperatures and building surface fraction in LCZ-2 and LCZ-5, but no relationship was present in other zones. There was a relationship between the surface temperature and building height in LCZ-3 and LCZ-5, however, no relationship was found in other zones.

Interpretation: The Local Climate Zone system developed by Oke and Stewart should be supported by technical research and field studies, and should be adapted in Turkish cities.

Key words: Local climate zone, Surface temperature, Thermal load, Urban heatisland

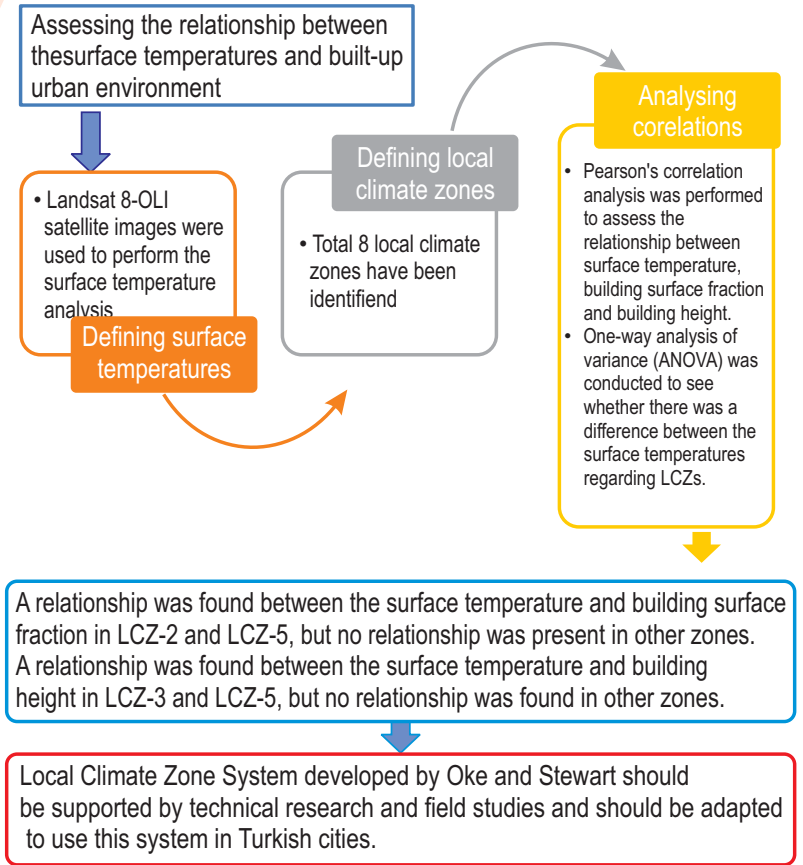

How to cite : Somuncu, D.H. and Ü. Yüksel: Assessment of relationship between the surface temperatures and built-up urban environment in Ankara city center. J. Environ. Biol., 41, 491-498 (2020). 


\section{Introduction}

The interest in urban climate has increased due to urban development boosted by a rapid increase in the global population (Středová et al., 2015), global climate change, and associated effects on local scale (Tyler and Moench, 2012). Determining changes in climate parameters-and demonstrating of the effects of changes on the urban ecosystem and people concerning urban morphology has gained importance for both urban residents and studies of urban planning.

The idea of dividing cities into climate zones has a long history in the field of urban climate (Wicki and Parlow, 2017). Chandler divided London (UK) into four climate regions in 1960s (Chandler, 1965), while Auer divided St. Louis (USA) into different climate zones by land use (Auer, 1978), and Weischet examined the effect of similar urban structures in Europe on the local climate in Freiburg (Germany) (Wicki and Parlow, 2017). This climatic classification seen in the German studies of 1980s was conceptualized by the term "climatope" and standardized through climate maps and VDI (Association of German Engineers) guidelines, but the search for different tools and concepts continued in USA and other countries.

Ellefsen (1991) made efforts to establish a relationship between urban morphology and climate parameters in a study covering ten USA cities. The system structure called "Urban Terrain Zones" by Ellefsen, classified the urban zones based on roads and structural materials.

People continued to study the relationship between urban morphology and climate parameters in 2000. Oke developed the classification system called "Urban Climate Zone" and divided cities into homogeneous regions using certain parameters such as urban structure density, permeability, aspect ratio, pattern, and aerodynamic roughness. Another significant development that took place in 2000 was the increase in the number of studies on technical development, urban climate and urban heat islands that investigated the relationship between the surface temperatures of larger areas covering cities and neighboring areas based on computer and satellite technologies, land characteristics and urban meteorological measurements. They contained models that indicated the need for developing common concepts and criteria for basic subjects, comparing the results of these studies with one another, and forming a systematic standard for using the results of these studies in different countries, regions or cities. Stewart and Oke $(a, b)$ generated the classification system of local climate zones to transform the urban heat island effect into a standard display. The Local Climate Zone (LCZ) system standardizes the characteristics regarding the built-up environment and land cover (building heights, tree heights, ground and concrete cover) according to relevant factors.

The LCZ system classification has been used in many cities as it has basic features that can be used in every city. The
LCZ system has been applied in Toulouse-France (Houet and Pigeon, 2011), Olomouc-Czech Republic (Lehnert et al., 2015), Novi Sad-Serbia (Savić et al., 2013); Szeged-Hungary (Unger et al., 2014), Nancy-France (Leconte et al., 2015), Dublin-Ireland (Alexander and Mills, 2014) in Europe, in Nagano-Japan (Stewart and Oke, 2009) and Colombo-Sri Lanka (Perera and Emmanuel, 2018) in Asia.

This study focused on analyzing the relationship between the surface temperatures of Ankara - the thermal load in this regard - and the built-up environment of the city using Local Climate Zone system. Moreover, it reviewed the practicability of applying the LCZ system developed by Oke and Stewart to Turkish cities, as well as determining its potential and limitations.

\section{Materials and Methods}

The capital city of Turkey, Ankara is located in Central Anatolia $\left(39^{\circ} \mathrm{N}, 32^{\circ} \mathrm{E}\right) 850 \mathrm{~m}$ above sea level with a population of $5,503,985$, was selected as study area. The area was in Köppen's Csa climatic zone (Yilmaz and Çiçek, 2018) with an annual mean temperature of $12^{\circ} \mathrm{C}$ and annual precipitation of $388.1 \mathrm{~mm}$ (Yılmaz and Kaymak, 2015).

While determining the study area in Ankara, three main alternatives were determined primarily in the city center and in new housing development areas of the metropolitan area. These alternative areas consisting of different land use/land cover and buildings with different heights were investigated first. Area covering twelve neighborhoods in the city center that featured the greatest variety about LCZ was selected as the study area (Fig. 1).

Landsat 8 satellite images were used to determine the urban surface temperatures. Landsat 8 is a 12-band display satellite produced by collaboration between NASA (National Aeronautics and Space Administration) and the United States Geological Survey (USGS). The $10^{\text {th }}$ and $11^{\text {th }}$ bands were used for
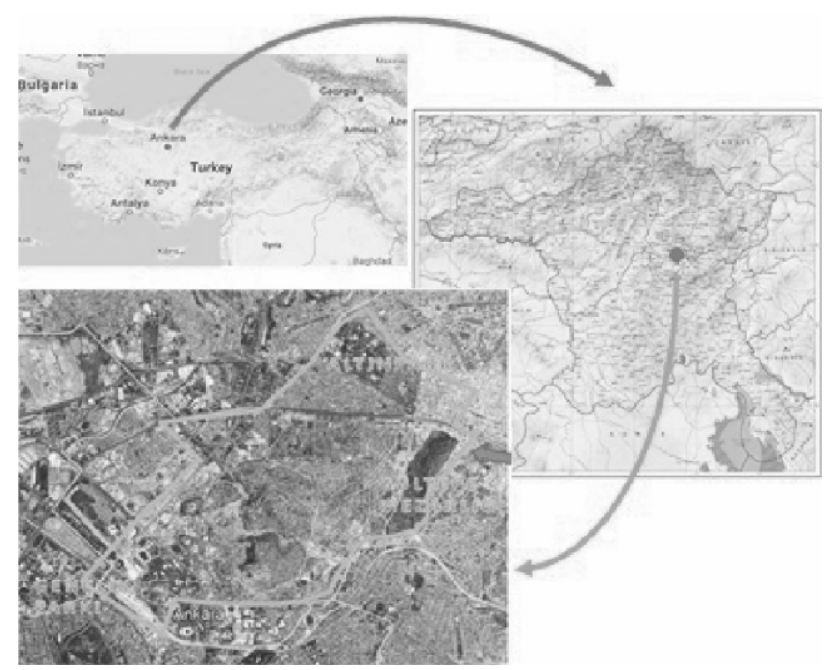

Fig. 1 : Study area. 
thermal imaging. The reason Landsat satellite images were preferred in this study as its resolution for thermal bands was greater than that of other satellites.

Google Earth images and 1/1000 maps obtained from the municipality were used for basic analyses of LCZ classification system. Land studies were performed using these maps and Google Earth images, and building-related data served as the basis for the analyses were updated and transferred to a Geographic Information System (GIS). Besides center road lines were formed using the maps and Google Earth images, and the data from the field study and figures regarding road width obtained from the maps were processed as feature data.

This study consisted of two basic stages: formation of thermal load map and analysis of the relationship between surface temperatures, LCZs, and the built-up environment by determining these LCZs. Metadata from Landsat 8-OLI (Operational Land Imager) satellite images were used to perform the surface temperature analysis, and the following formulas were used with the Raster Calculator in ArcGIS:

Conversion of reflection value here to a spectral radiance figure (Yılmaz, 2015; Şekertekin and Marangoz, 2019).

$$
S R=M L{ }^{*} Y D+A L
$$

Conversion of reflection value to energy spread (YıImaz, 2015; Şekertekin and Marangoz, 2019).

$$
\mathrm{TK}=(\mathrm{K} 2 /(\ln (\mathrm{K} 1 / \mathrm{SR})+1))
$$

Conversion of Kelvin energy value to Celsius scale.

$$
\mathrm{TC}=\mathrm{T} \mathrm{K}-273.15
$$

A field study was conducted, and building height data were transferred to the maps. These data were later transferred to digital media through ArcGIS program. Building height data were classified using the height figures employed in the classification system developed by Stewart and Oke (2012).

Three height levels are determined according to this system (Fig. 2). Buildings lower than eight meters were classified as low buildings while the ones reaching 10 to $20 \mathrm{~m}$ were classified as moderate-height buildings, and buildings higher than $25 \mathrm{~m}$ were classified as high buildings.

The data related to building floor areas were used for surface fraction analysis. While performing this analysis, the maps were updated by conducting field studies and relating the results to the Google Earth images. The data were updated by adding new buildings in place of demolished buildings in the neighborhoods with shanties that were regarded as urban transformation areas.

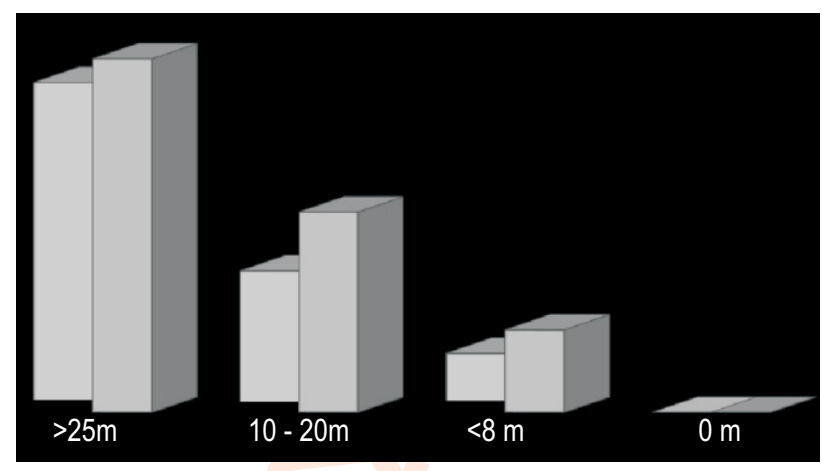

Fig. 2 : Height figures regarding the classification system of LCZs (Stewart and Oke, 2012).

The LCZs in the study area were determined by considering the criteria defined by Stewart and Oke (2012). Evidence indicated that there were eight LCZs in the area. The characteristics and appearance of these zones are presented in Table 1.

The surface temperature data regarding the LCZs obtained from the satellite image were transferred to the IBM SPSS-24 software program, and distribution of data was reviewed. Forty-one extreme measurements, fifteen of which were related to surface temperature and twenty-six of which were related to building surface area, were excluded from the data set. Before examining the relationship between surface temperatures, building height and building surface area, a normality test and Levene's test for homogeneity of variance were conducted to determine whether the relationship was parametric or non-parametric. The histogram chart, skewness and kurtosis figures regarding the distribution of the measurements for surface temperature, building height and building surface fraction, all the three continuous variables, were assessed for normality analyses (Table 2). The results indicated that the skewness and kurtosis figures ranged between -1 and +1 . The research indicated that skewness and kurtosis coefficients can range between -1 and +1 , which is a criterion of the normality hypothesis (Morgan et al., 2004). The homogeneity of test variances,-or the distribution of Levene's test of homogeneity of variance indicated that the test variances displayed a homogeneous distribution $(p>0.05)$. The figures regarding the measurements were continuous data at the level of scale with equal intervals. Two samples (groups) were independent-of each another, the dependent variables were measured at interval or ratio scale level, and normality and homogeneity assumptions were ensured, which met the assumptions and criteria related to parametric test (Köklü et al., 2007).

Pearson's correlation analysis was performed to assess the relationship between surface temperature, building surface fraction and building height. One-way analysis of variance (ANOVA) was conducted to check a difference between the 
Table 1: Characteristics and visuals of LCZzones

\begin{tabular}{|c|c|c|c|}
\hline LCZ & $\begin{array}{c}\text { Google Earth/ } \\
\text { Texture }\end{array}$ & Photo & Features \\
\hline LCZ2 & $\nabla$ & & Compact areas with 3-8 story buildings (green areas are generally limited) \\
\hline LCZ3 & & 8 & Compact areas with 1-3 story buildings (green areas are generally limited) \\
\hline LCZ4 & & & Areas with broad layouts and higher than 10 story buildings \\
\hline LCZ5 & & & Areas with broad layouts and $3-8$ story buildings \\
\hline LCZ7 & & & Disorganized residential areas with dense, $1-2$ story buildings (residential areas with shanties) \\
\hline LCZ8 & & & Areas with large $2-3$ story buildings coated with impervious materials \\
\hline LCZA & & & Green areas with dense trees \\
\hline LCZE & & & Areas covered with rocks or large, impermeable surfaces \\
\hline
\end{tabular}

Table 2: Skewness and Kurtosis figures for the data

\begin{tabular}{lll}
\hline & Skewness & Kurtosis \\
\hline Surface temperature & -0.769 & 0.958 \\
Building surface fraction & 0.988 & 0.652 \\
Building height & 0.733 & 0.896 \\
\hline
\end{tabular}

surface temperatures regarding LCZs. Tukey's test, one of multiple comparison (Post Hoc) tests used in one-way variance analysis, was performed to compare the groups with one another to see significant difference between the variables of more than two groups (Can, 2014).

\section{Results and Discussion}

Area that had the highest building fraction rate in the study area was the region hosting shanties, east of the Kale Neighborhood. Areas with the lowest building surface fraction rate were the regions in Gültepe, Aktaş and Atıfbey neighborhoods with high buildings (Fig. 3). According to the building surface fraction figures classified by LCZs (Table 3), the minimum building surface fraction was found in LCZ-3, while the maximum building surface fraction was in LCZ-7. Regarding the mean building surface fraction figures, the highest building surface fraction figure was seen in LCZ-7, while the lowest was displayed by LCZ-8.

Atıfbey, Kale and Yıldırım Beyazıt neighborhoods were the regions with the lowest building heights. The heights of buildings in the Altınpark, Aydınlıkevler and Ziraat neighborhoods ranged between 10 and $20 \mathrm{~m}$. For the Aktaş and Gültepe neighborhoods, buildings constructed by the Public Housing Administration within the urban transformation context had the 


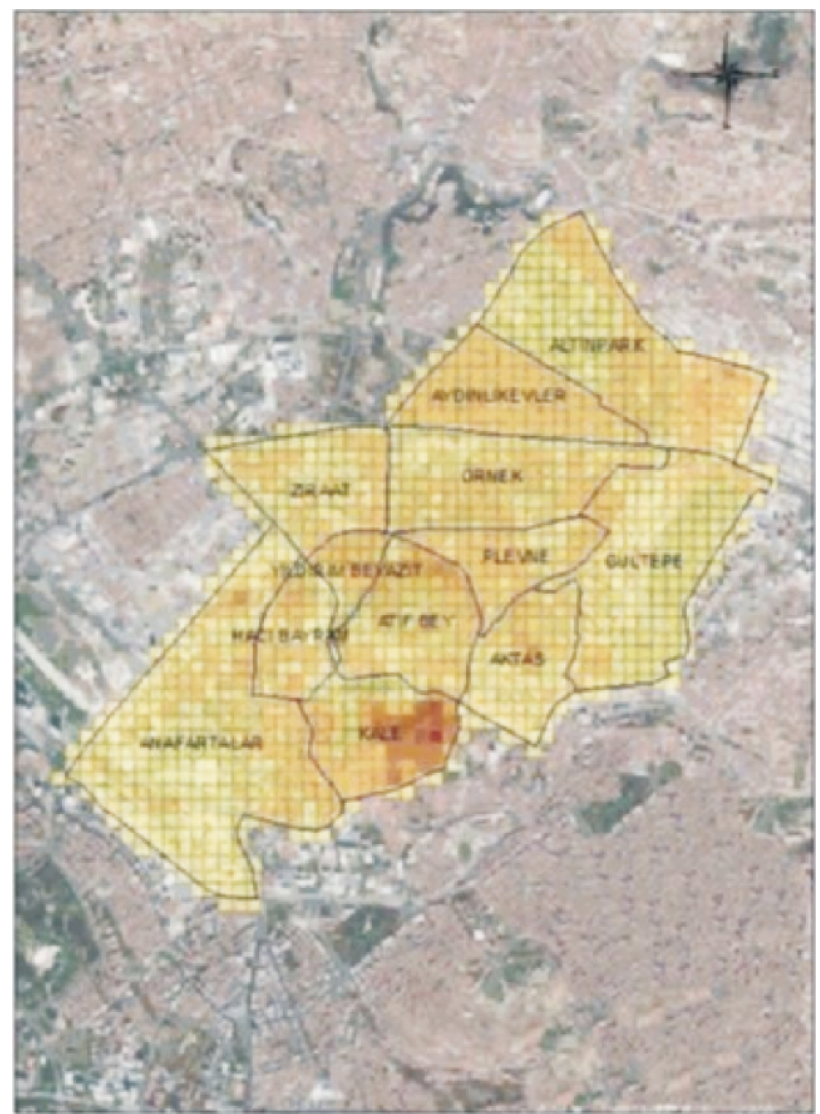

Legend

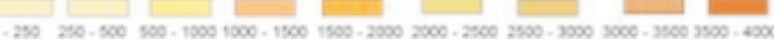

Fig. 3 : Building surface fraction analysis.

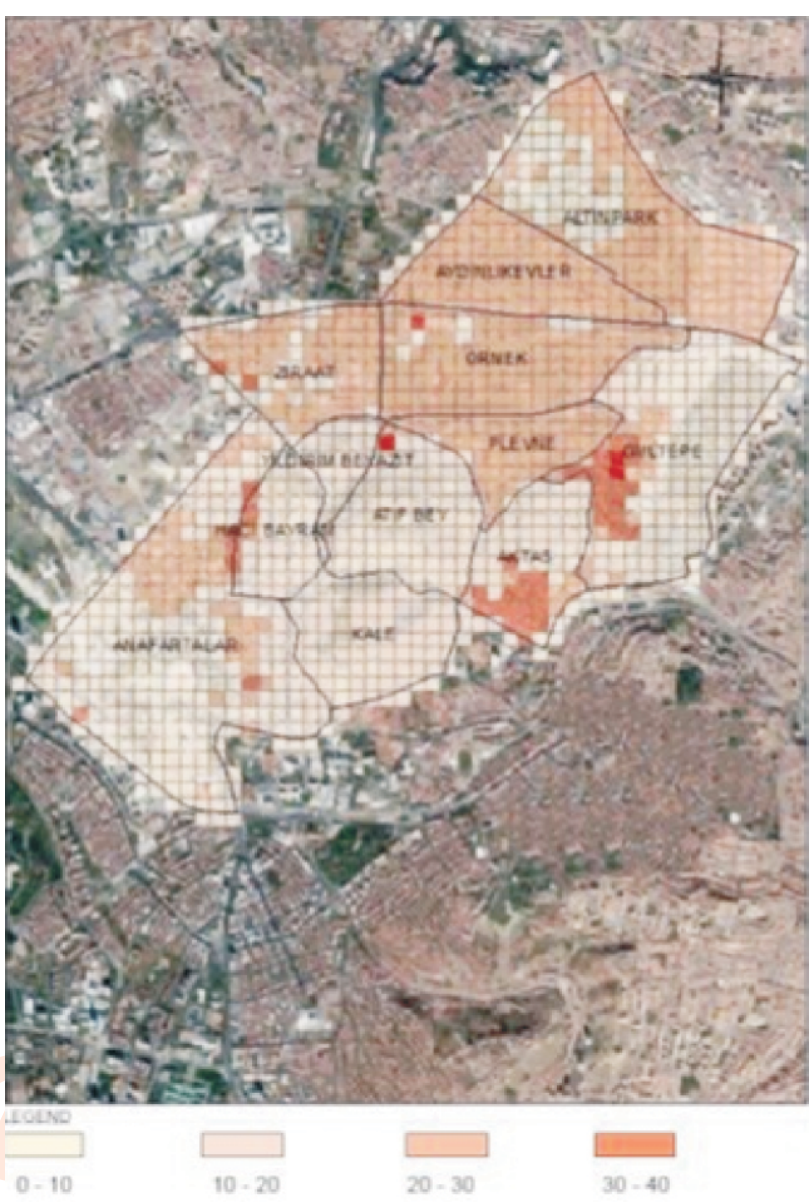

Fig. 4 : Building height analysis.

Table 3 : Building surface fraction and heights

\begin{tabular}{|c|c|c|c|c|c|c|c|c|c|}
\hline \multirow[t]{2}{*}{ LCZClass } & \multicolumn{3}{|c|}{ Building Surface Fraction } & \multicolumn{3}{|c|}{ Building Height (m) } & \multicolumn{3}{|c|}{ Surface Temperatures $\left({ }^{\circ} \mathrm{C}\right)$} \\
\hline & Min & Max & Mean & Min & Max & Mean & Min & Max & Mean \\
\hline LCZ2 & 57.7 & 1584.6 & 668.4 & 9.0 & 20.0 & 12.8 & 37.1 & 41.0 & 39.5 \\
\hline LCZ3 & 40.9 & 2391.1 & 715.3 & 7.0 & 8.0 & 7.1 & 37.0 & 41.0 & 39.2 \\
\hline LCZ4 & 86.4 & 1195.1 & 389.2 & 25.0 & 38.0 & 27.2 & 38.6 & 41.3 & 40.0 \\
\hline LCZ5 & 49.7 & 850.6 & 433.2 & 9.0 & 24.0 & 14.2 & 37.0 & 42.0 & 39.1 \\
\hline LCZ7 & 71.5 & 3601.9 & 1037.6 & 7.0 & 8.0 & 7.1 & 37.0 & 42.3 & 39.9 \\
\hline LCZ8 & 44.0 & 824.9 & 332.4 & 7.0 & 15.0 & 7.9 & 36.5 & 44.5 & 39.7 \\
\hline LCZA & - & - & - & - & - & - & 33.0 & 40.5 & 36.8 \\
\hline LCZE & - & - & - & - & - & - & 37.0 & 42.0 & 39.3 \\
\hline
\end{tabular}

Table 4 : Results of Pearson's Correlation Analysis regarding relationship between surface temperatures and building surface fraction

\begin{tabular}{llll}
\hline & $\mathbf{N}$ & $\mathbf{r}$ & $\mathbf{p}$ \\
\hline Building surface fraction & 1214 & $0.33\left(^{*}\right)$ & 0.000 \\
Building height & 1214 & $0.30\left(^{*}\right)$ & 0.000 \\
\hline
\end{tabular}

${ }^{*} p<0.05$ 


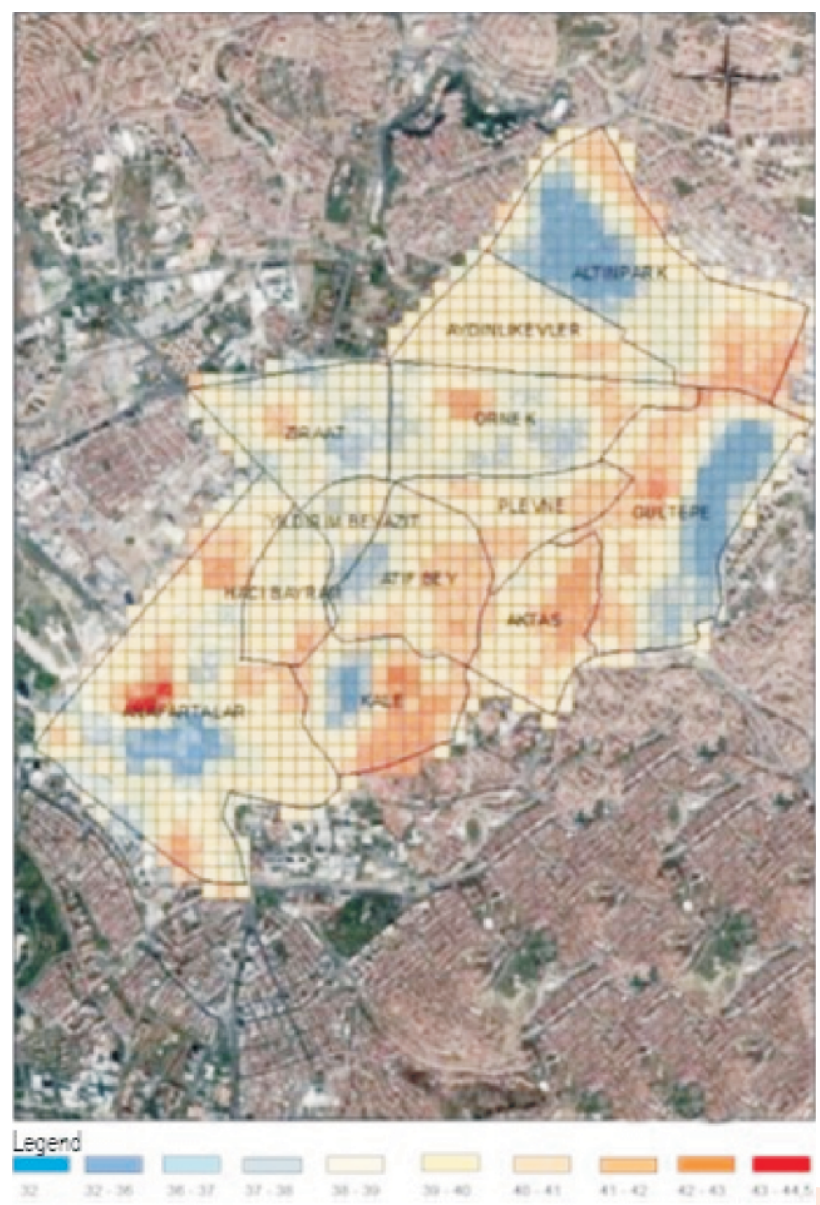

Fig. 5 : Surface temperature analysis.

greatest height figures in this study (Fig. 4). Building heights by LCZs are presented in Table 3. According to the assessment of building heights by LCZs, the minimum building height was seen in LCZ-3, LCZ-7 and LCZ-8, while the maximum was seen in LCZ4. The mean building height figures indicate that the highest figure belonged to LCZ-4, while the lowest was displayed by LCZ-3 and LCZ-7.

The surface temperatures determined by analyzing Landsat 8-OLI satellite images indicated that the mean temperature in the area ranged from $33.0^{\circ} \mathrm{C}$ to $44.5^{\circ} \mathrm{C}$. The areas with the highest surface temperature were the northside of Gençlik Park in the Anafartalar neighborhood, the zone at the southeast of Kale Park within the borders of the Kale neighborhood, and the Gültepe and Aktaş neighborhoods. The lowest surface temperature was seen in Altınpark in the north, Gültepe Graveyard in the east, and Gençlik Park in the south (Fig.5).

According to the assessment of surface temperatures by LCZs (Table 3), the lowest temperature $\left(33.0^{\circ} \mathrm{C}\right)$ was seen in $\mathrm{LCZ}-\mathrm{A}$ with a dense tree pattern, while the highest figure $\left(44.5^{\circ} \mathrm{C}\right)$ was detected in LCZ-8, which has buildings with low stories on a broad base and impervious neighboring areas.

The relationship between the surface temperatures and building surface fraction figures obtained from satellite images (Table 4) indicate that there was a positive significant relationship slightly above the low significance level between surface temperatures and building surface fraction $(r=0.33)(p=0.000)$. A positive relationship with a low significance level was found between surface temperatures and building heights $(r=0.30)(p=$ 0.000).

Examining of LCZs indicated a significant difference between the surface temperatures obtained from the satellite images $\left(F_{(7-1206)}=119.22\right)(p=0.000)($ Table 5). This difference was seen in the following results: The surface temperatures of LCZ-3 ( $=40.01$ ) and LCZ-4 (= 39.97) were higher than those of LCZ-5 (= 39.14), LCZ-A ( = 37.03) and LCZ-E ( = 39.29); the surface temperatures of LCZ-A $(=37.03)$ were lower than those of LCZ-5 ( = 39.14), LCZ-7 ( = 39.81), LCZ-8 ( = 39.71) and LCZ-E ( = 39.29). This study evaluated relationship between surface temperature and building fractions in terms of LCZs. A relationship was found between the surface temperature and building surface fraction in LCZ-2 and LCZ-5, but no relationship was present in other zones $(p<0.05)$. (The relationship in LCZ-A and LCZ-E could not be calculated as the building surface fraction was zero.)

Regarding LCZ-2, there was a positive significant relationship that was slightly above the low significance level between surface temperatures and building surface fraction $(r=$ $0.15)(p=0.009)$, which was the highest significance level in this study. Regarding LCZ-5, there was a negative significant relationship that was slightly above the low significance level between surface temperatures and building surface fraction $(r=$ $-0.16)(p=0.03)$, which was the lowest level of significance in this study (Table 6). Relationship between surface temperature and building height (Table 6) was observed in LCZ-3 and LCZ-5 $(p<0.05)$, but no relationship was found in other zones. (The relationship in LCZ-A and LCZ-E could not be calculated, as the building surface fraction was zero).

Regarding LCZ-3, a positive significant relationship that was slightly above the moderate significance level between surface temperatures and building surface fraction $(r=0.33)$ $(p=0.000)$, which is one of the highest levels of significance in this study. Regarding LCZ-5, there was a negative significant relationship that was slightly above the low significance level between surface temperatures and building surface fraction $(r=$ -0.15) ( $p=0.020)$, which was one of the lowest levels of significance in this study.

Many studies have recently been conducted to determine the changes in urban climate parameters to identify the heat 
Table 5: Results of One-Way ANOVAregarding difference between the surface temperatures by LCZs

\begin{tabular}{|c|c|c|c|c|c|c|c|}
\hline & LCZ & $\mathbf{N}$ & & $S$ & $F(7-1206)$ & $p$ & Post Hoc (Tukey) \\
\hline \multirow{8}{*}{$\begin{array}{l}\text { Surface } \\
\text { temperature }\end{array}$} & LCZ-2 & 241 & 39.53 & 0.74 & \multirow[t]{8}{*}{119.22} & \multirow[t]{8}{*}{$0.000^{*}$} & \multirow{8}{*}{$\begin{array}{l}4<2,7<2,8<2, \\
3>4,3>7,3>8,1>7, \\
4>7,5>7,6>7,8>7\end{array}$} \\
\hline & LCZ-3 & 139 & 40.01 & 0.92 & & & \\
\hline & LCZ-4 & 50 & 39.97 & 0.64 & & & \\
\hline & LCZ-5 & 191 & 39.14 & 0.97 & & & \\
\hline & LCZ-7 & 173 & 39.81 & 1.17 & & & \\
\hline & LCZ-8 & 26 & 39.71 & 1.81 & & & \\
\hline & LCZ-A & 155 & 37.03 & 1.44 & & & \\
\hline & LCZ-E & 239 & 39.29 & 1.10 & & & \\
\hline
\end{tabular}

${ }^{*}$ P<0.05; Categories: LCZ-2=1; LCZ-3=2; LCZ-4=3; LCZ-5=4; LCZ-7=5; LCZ-8=6; LCZ-A=7; LCZ-E=8

Table 6 : Results of Pearson's Correlation Analysis regarding relationship between surface temperature, building surface fraction and building height in terms of LCZs

\begin{tabular}{|c|c|c|c|c|c|c|}
\hline & \multirow{2}{*}{$\begin{array}{l}N=121 \\
N\end{array}$} & & \multicolumn{2}{|c|}{ Building surface fraction } & \multicolumn{2}{|c|}{ Building height } \\
\hline & & & $r$ & $\mathrm{p}$ & $r$ & $\mathrm{p}$ \\
\hline LCZ-2 & 241 & Surface temperature & $0.15^{*}$ & 0.009 & -0.06 & 0.197 \\
\hline LCZ-3 & 139 & Surface temperature & 0.07 & 0.215 & $0.33^{*}$ & 0.000 \\
\hline LCZ-4 & 50 & Surface temperature & -0.21 & 0.071 & -0.12 & 0.203 \\
\hline LCZ-5 & 191 & Surface temperature & $0.16^{*}$ & 0.013 & $-0.15^{\star}$ & 0.020 \\
\hline LCZ-7 & 173 & Surface temperature & 0.06 & 0.215 & 0.05 & 0.272 \\
\hline LCZ-8 & 26 & Surface temperature & -0.21 & 0.157 & -0.03 & 0.435 \\
\hline
\end{tabular}

${ }^{*} p<0.05$

islands and surface temperatures. Urban climate studies that reveal the relationship between urban morphology, land cover, construction materials, traffic, anthropogenic heat resources, and thermal conditions, emphasize the formation of tools for using climate-related information in studies of thermal load explanations and planning (Perera and Emmanuel, 2018).

The LCZ classification system developed by Stewart and Oke makes the results comparable and observable by reviewing the urban thermal conditions and urban heat islands through standard parameters,-and ensures the generation of spatial climate data that could pave the way for planning studies. Results of this study indicate that the LCZ system should be supported by technical research and adapted to the building pattern to use this system in Turkish studies. In addition, climate classes should be observed in the studies of LCZ adaptation in Turkey where ten different Köppen climate classes can be seen (Yılmaz and Çiçek, 2018), and it should be noted that this difference is significant when providing input to planning and design studies.

\section{References}

Alexander, P. and G. Mills: Local climate classification and Dublin's urban heat island. Atmosphere, 5, 755-774 (2014).

Auer, Jr. A.H.: Correlation of land use and cover with meteorological anomalies. J. Appl. Meteorol., 17, 636-643 (1978).
Can, A.: SPSS ile bilimsel araştırma sürecinde nicel veri analizi (Quantitative data analysis in scientific research process with SPSS) $2^{\text {nd }}$ Edn., Pegem, Ankara (2014).

Chandler, T.J.: The climate of London. Hutchinson \& Co. Publishers LTD. London (1965).

Ellefsen, R.: Mapping and measuring buildings in the canopy boundary layer in ten US cities. Energy and Buildings, 16,1025-1049(1991).

Houet T. and G. Pigeon: Mapping urban climate zones and quantifying climate behaviours - An application on Toulouse urban area (France). Environ. Pollut., 159, 2180-2192 (2011).

Köklü, N., Ş. Büyüköztürk and Ç.Ö. Bökeoğlu: Sosyal bilimler için istatistik (Statistics for social sciences). Pegem, Ankara (2007).

Leconte, F., J. Bouyer, R. Claverie and M. Pétrissans: Estimation of spatial air temperature distribution at sub-mesoclimatic scale using the LCZ scheme and mobile measurements. In: Proceedings of 9th International Conference on Urban Climate (ICUC9) jointly with 12th Symposium on the Urban Environment, Toulouse, France.

Lehnert, M., J. Geletič, J. Husák and M. Vysoudil: Urban field classification by "local climate zones" in a medium-sized Central European city: the case of Olomouc (Czech Republic). Theoret. Appl. Climatol., 122, 531-541(2015).

Morgan, G.A., N.L. Leech, G.W. Gloeckner and K.C. Barrett: SPSS for introductory statistics: Use and Interpretation. Psychology Press (2004).

Oke T.R.: Initial guidance to obtain representative meteorological observations at urban sites. IOM Report 81, World Meteorological Organization, Geneva (2004). 
Perera N.G.R. and R.A. Emmanuel: 'Local Climate Zone' based approach to urban planning in Colombo, Sri Lanka. Urban Climate, 23, 188-203 (2018).

Rosenzweig, C., W.D. Solecki, S.A. Hammer and S. Mehrotra: Climate change and cities: First assessment report of the urban climate change research network. Cambridge University Press (2011).

Savić, S., D. Milošević, L. Lazić, V. Marković and D.P. Arsenović: Classifying Urban Meteorological Stations Sites by "Local Climate Zones": Preliminary Results for the City of Novi Sad (Serbia). Geographica Pannonica, 17, 60-68 (2013).

Şekertekin, A. and A. Marangoz: Zonguldak Metropolitan Alanındaki Arazi Kullanımı Arazi Örtüsünün Yer Yüzey Sıcaklığına Etkisi (The Impact of Land Use Land Cover on Land Surface Temperature in Zonguldak MetropolitanArea). Geomatik., 4, 101-111 (2019).

Stewart, I. D. and T.R. Oke(a): Classifying urban climate field sites by "local climate zones": The case of Nagano, Japan. In: Seventh International Conference on Urban Climate., 29 (2009).

Stewart, I.D. and T.R. Oke(b): Local climate zones for urban temperature studies. Bull. Ameri. Meteorol. Soc., 93, 1879-1900 (2012).

Středová, H., T. Středa and T. Litschmann: Smart tools of urban climate evaluation for smart spatial planning. Moravian Geograp. Rep., 23, 47-57 (2015)

Tyler, S. and M. Moench: A framework for urban climate resilience. Climate and Development, 4, 311-326 (2012).

Unger, J., E. Lelovics and T. Gál: Local climate zone mapping using GIS methods in Szeged. Hung. Geograp. Bull., 63, 29-41 (2014).

Wicki, A. and E. Parlow: Attribution of local climate zones using a multitemporal land use/land cover classification scheme. J. Appl. Remote Sens., 11, 026001 (2017).

Yılmaz, E.: Landsat Görüntüleri İle Adana Yüzey Isı Adası (Adana surface heat island with Landsat satellite imagery). Coğrafi Bilimler Dergisi, 13, 115-138 (2015).

Yılmaz, E. and I. Çiçek: Detailed Köppen-Geiger climate regions of Turkey. J. Human Sci., 15, 225-242 (2018).

Yılmaz, F. K. and H. Kaymak: Çanakkale ve Ankara Meteoroloji İstasyonlarında Kaydedilen Günlük Yağış Verileri Üzerine Bir Analiz (An Analyse Upon Recorded Daily Precipitation Data in Çanakkale and Ankara Meteorological Stations). Atatürk Üniversitesi Sosyal Bilimler Enstitüsü Dergisi, 19, 329-348 (2015). 